\title{
Análisis de los procesos de regresión y restitución del monumento natural Puente del Inca, Andes Centrales, Provincia de Mendoza, Argentina
}

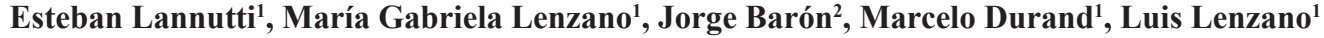

\author{
I Instituto Argentino de Nivología, Glaciología y Ciencias Ambientales (IANIGLA)-CCT, CONICET, Av. Ruiz Leal s/n, Parque General \\ San Martín, Mendoza, Argentina. \\ elannutti@mendoza-conicet.gob.ar; mlenzano@mendoza-conicet.gob.ar; mdurand@mendoza-conicet.gob.ar; llenzano@ \\ mendoza-conicet.gob.ar \\ 2 Instituto de Estudios del Ambiente y Recursos Naturales (IDEARN), Universidad Nacional de Cuyo, Centro Universitario, Parque \\ General San Martin, Mendoza, Argentina. \\ jbaron@uncu.edu.ar
}

\begin{abstract}
RESUMEN. El Puente del Inca, próximo a la villa homónima, es un puente natural que se emplaza sobre el río Cuevas, a unos 2.700 m s.n.m. en los Andes centrales de la provincia de Mendoza, Argentina. Declarado Monumento Natural Provincial en el año 2005, desde principios del siglo XX se ha registrado en él un continuo deterioro, relacionado, principalmente, con procesos erosivos que provocan desprendimientos de parte del material que compone su estructura. El objetivo de este estudio es determinar qué factores son los que intervienen en la regresión y restitución estructural del puente natural. Para ello se recurrió a su inspección visual, a la caracterización de los manantiales termales, la medición de la tasa de acreción-erosión de los depósitos de travertino, el ensayo de materiales y el desarrollo de un modelo numérico estructural por el Método de los Elementos Finitos. Los resultados obtenidos indican que el deterioro está ligado, en su mayoría, a cambios en el sistema geobiológico que regula la depositación del travertino y a lo heterogéneo de la estructura del puente. Los cambios del sistema geobiológico están supeditados a variaciones en la actividad de las aguas termales presentes en la zona, cuya discontinuidad y/o fluctuaciones en el caudal están influenciadas tanto por factores naturales como antrópicos. La heterogeneidad de la estructura condiciona la estabilidad del monumento debido a la presencia de un material menos resistente en la parte inferior del tramo del puente. A partir de la simulación numérica, se determinaron factores de seguridad entre 1,5 y 3 en los sectores más afectados, por lo que la estructura es estable frente a su propio peso, siempre y cuando el puente mantenga las condiciones actuales.
\end{abstract}

Palabras clave: Puente de Travertino, Sistema geobiológico, Puente del Inca.

\begin{abstract}
Analysis of the deterioration and restoration processes in the natural monument Puente del Inca, Central Andes, province of Mendoza, Argentina. The Puente del Inca, next to the homonymous village, is a natural bridge located on the Cuevas River, at about 2,700 m above sea level in the Central Andes of the province of Mendoza, Argentina. Declared Provincial Natural Monument in 2005, since the beginning of the $20^{\text {th }}$ century it has registered a continuous weakening, mainly related to erosive processes that cause detachments of part of the material that makes up its structure. The objective of this study is to determine the factors involved in the structural regression and restitution of the natural bridge. To achieve this, visual inspection, characterization of thermal springs, measurement of accretionerosion rate of travertine deposits, testing of materials and the development of a structural numerical model by the Finite Element Method, were carried out. Results indicate that the deterioration is linked, mainly, with changes in the geobiological system that regulates the travertine deposition and to the heterogeneous structure of the bridge. Changes of the geobiological system are related to the activity of the thermal waters present in the area, whose discontinuity and/or fluctuations in the flow rate are influenced by both natural and anthropogenic factors. The heterogeneity of the structure conditions the stability of the monument due to the presence of a less resistant material in the lower part of the bridge arch. From the numerical simulation, safety factors between 1.5 and 3 were determined for the bridge, thus, we conclude the structure is stable against its own weight, as long as the bridge maintains the current conditions.
\end{abstract}




\section{Introducción}

El Puente del Inca (3249'34” S, 6954'41” W) es una estructura natural en forma de puente que se erige sobre el río Cuevas, en la provincia de Mendoza, Argentina, próxima al límite internacional con Chile (Fig. 1). Su particular morfología y valor paisajístico e histórico, lo convierten en un importante rasgo de identidad cultural para esta región de los Andes centrales. El puente es una geoforma natural constituida por travertino y material detrítico cementado, en cuya conformación incide la acción termomineral de las aguas que surgen en la zona. Rubio et al. (1993) afirman que este puente no es una estructura geológica rígida, sino que se trata de una "bioconstrucción mineral", en la que participan varios componentes que definen el perfil de la estructura, es decir, la existencia de colonias de algas, salinidad y temperatura del agua termal, presión parcial de los gases disueltos, velocidad y turbulencia del agua termal y gradiente de luminosidad. En este sentido, el Puente del Inca puede ser considerado como un "Sistema Geobiológico", en cuya formación interactúan procesos biológicos, físicos, químicos y geológicos (Lannutti et al., 2017). La morfología del puente es la resultante de un equilibrio entre agentes erosivos -naturales y antrópicos- y los procesos geobiológicos que continúan actualmente con la fase de formación de travertino y la cementación de material. Este equilibrio se ve afectado por la discontinuidad en el caudal y en la surgencia de las aguas termales, hecho que impacta negativamente en la estabilidad estructural del puente.

Estudios realizados sobre el Puente del Inca, como los de Kittl (1941), Monteverde (1967), Ramos (1993), Rimoldi (1993) y Rubio et al. (1993), ya advierten del estado de deterioro de la estructura. Es por ello que, debido a la vulnerabilidad y al valor patrimonial que lo caracteriza, resulta importante ahondar en el conocimiento cualitativo y cuantitativo de aquellos procesos que deterioran/restablecen su integridad a partir de estudios y métodos ingenieriles de nulo impacto sobre el puente; entre ellos: sensoramiento remoto, ensayo en laboratorios y generación de modelos computacionales para la simulación numérica de estabilidad. A partir de esto, se pretende contribuir al conocimiento de la situación actual del puente a fin de que permita en el futuro abordar la toma de decisiones en relación con su preservación y restauración.

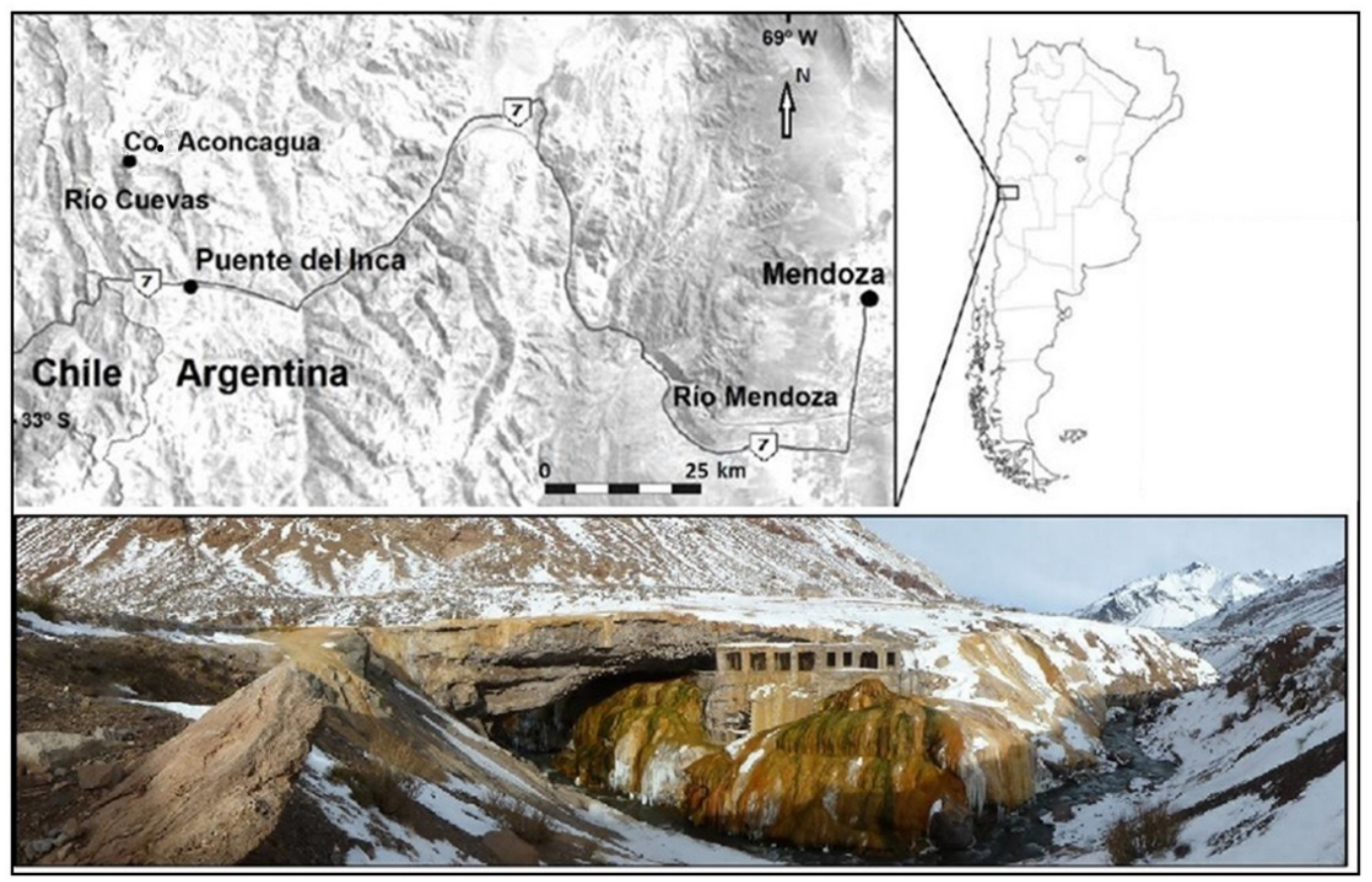

FIG. 1. Esquema de ubicación del Puente del Inca. Vista general de la estructura natural emplazada sobre el río Cuevas. 


\section{Consideraciones generales y área de estudio}

\subsection{Depósitos de travertino}

La palabra travertino se habría originado a partir de lapis travertinus, terminología utilizada en los depósitos termales de Bagni di Tivoli en Lazio, Italia (Pentecost, 2005). Según Fouke et al. (2000) el término travertino incluye "cualquier precipitación de carbonato no marino, formado en o cerca de fuentes termales terrestres, ríos, lagos y cuevas". La gran mayoría de los travertinos se originan a partir de la desgasificación de las aguas subterráneas ricas en dióxido de carbono $\left(\mathrm{CO}_{2}\right)$ y una concentración de calcio mayor a $2 \mathrm{mmol} / \mathrm{L}$ (Pentecost, 2005). El proceso de deposición de travertino se inicia cuando el agua termal surge a la superficie y entra en contacto con la atmósfera y libera $\mathrm{CO}_{2}$ disuelto, reacción que es acompañada por la precipitación de carbonato de calcio. Este proceso se representa por la reacción:

$$
\mathrm{Ca}^{2+}+2\left(\mathrm{HCO}_{3}^{-}\right)=\mathrm{CaCO}_{3}+\mathrm{CO}_{2}+\mathrm{H}_{2} \mathrm{O}
$$

Al mismo tiempo existe, frecuentemente, una pérdida adicional de $\mathrm{CO}_{2}$ relacionada con procesos biológicos que promueven la precipitación del $\mathrm{CaCO}_{3}$ a partir del crecimiento de comunidades microbianas. En este sentido, las aguas termales fomentan un "sistema geobiológico" en el que la interacción de procesos biológicos, físicos y químicos favorecen la deposición de travertino (Fouke, 2011).

\subsection{Descripción del área}

El Puente del Inca es una estructura natural que se erige sobre el río Cuevas en el ámbito de la cordillera Principal de los Andes centrales. La estructura forma un puente suspendido a 19,2 m sobre el nivel del río, el que posee una longitud de $53,4 \mathrm{~m}$, un ancho de $27,6 \mathrm{~m}$ y un espesor de 10,2 $\mathrm{m}$. La geoforma tiene un perfil redondeado y asimétrico con forma mixta entre un puente en arco (estribo este) y un puente en viga (estribo oeste) (ver fotografía de la tabla 1). $\mathrm{Su}$ cubierta presenta un colorido particular en los tonos del verde, naranja, amarillo y ocre, teñido por el crecimiento de comunidades microbianas y de las aguas termales que depositan capas de minerales sobre su superficie. A fines del siglo XIX, comenzó la explotación de las fuentes termales como estación balneológica, mediante la construcción de un lujoso hotel, un pabellón de baños termales y un túnel para comunicar ambos edificios. En el año 1965 un gran alud causó destrozos en la estructura del hotel, lo que ocasionó el abandono del lugar y el fin de la explotación de las termas (Ramos et al., 2008). Actualmente, si bien ya no se realiza actividad balneológica en el Puente del Inca, el monumento es visitado por un gran número de turistas que llegan al lugar para apreciar su paisaje y las antiguas instalaciones de los baños termales (Fig. 1).

El río Cuevas es un río de montaña alimentado por aguas de deshielo cuyas nacientes se localizan en la quebrada de Matienzo, última quebrada previa al sector limítrofe entre Argentina y Chile. Esta corriente de agua es parte de un conjunto de ríos tributarios cuyo colector principal es el río Mendoza. Sobre la margen occidental del puente existen fuentes termales $\left(35^{\circ} \mathrm{C}\right)$ que bañan la zona superficial de la geoforma y desagotan en el río Cuevas. Estas tendrían su origen a partir de aguas meteóricas que habrían percolado en zonas de falla y que a posteriori ascendieron por presión hidrostática (Ramos, 1993; Aguirre Urreta y Ramos, 1996). Debido a su temperatura, estos autores también sugieren que el calentamiento del agua es producto del gradiente geotérmico normal. Estas fuentes, ricas en dióxido de carbono, tienen condiciones propicias para establecer un sistema geobiológico de formación y depositación de travertino. Ferrari et al. (2002) estudiaron el crecimiento cianobacteriano en el Puente del Inca y corroboraron la participación biológica en la precipitación de carbonato de calcio, producida por el crecimiento fotosintético de estas comunidades microbianas. Por lo tanto, el puente natural está constituido por depósitos de travertino y material detrítico cementado con este carbonato, producto de la actividad hidrotermal y biológica.

\subsection{Génesis del puente}

Desde mediados del siglo XIX, diversos autores plantearon la posible génesis del puente natural. Si bien existen diversas hipótesis acerca de su origen, todas ellas hacen referencia a la incidencia de la actividad hidrotermal y al rol del río Cuevas como agente modelador del paisaje y de parte de la morfología actual de puente (Darwin, 1838; Schiller, 1907; Kittl, 1941; Monteverde, 1947; Ramos, 1993; Aguirre Urreta y Ramos, 1996). En la teoría más reciente, Fauqué et al. (2009) plantean que la génesis está asociada 
TABLA 1. RESUMEN DE LAS EVIDENCIAS DE FALLAS EN LAS ESTRUCTURAS RELACIONADAS CON EL DETERIORO DE PUENTE DEL INCA Y LA INCIDENCIA EN SU ESTABILIDAD.

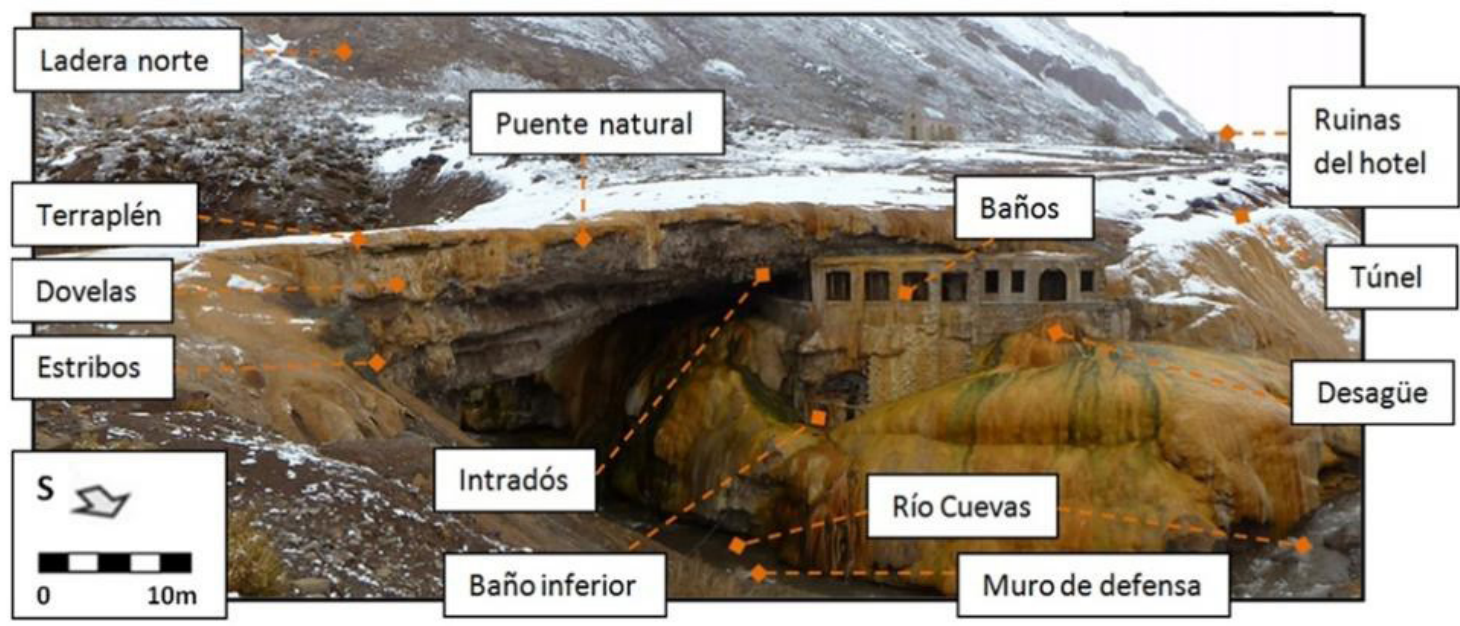

Evidencias de fallas

Causas

Consecuencia

Incidencia

Deterioro en dovelas y estribos.

Deterioro en la parte media del arco.

Agrietamiento y resecado de la cubierta/ terraplén del puente.

Caída de estalactitas en intradós.

Erosión en dovela noreste.

Erosión en ribera sur del río Cuevas adyacente al estribo oeste.

Sectores del puente con mayores registros de caídas de rocas.

Socavación de los estribos.

Carga nívea sobre la estructura del arco.
Desgaste y desprendimientos relacionados con la erosión por acción del agua y eólica, meteorización y factores sísmicos.

Desgaste y desprendimientos relacionados con la erosión por acción del agua y eólica, meteorización y factores sísmicos.

Erosión por acción del agua y eólica, meteorización y factores sísmicos. Disminución de la surgencia de fuentes termales.

Desgaste y desprendimientos relacionados con la erosión por acción del agua y eólica, meteorización y factores sísmicos.

Anidamiento y permanencia de palomas.

Remoción en masa, aluviones y avalanchas provenientes de la ladera norte.

Debilidad en el material, sectores con altas tensiones, deformaciones y bajos factores de seguridad.

Erosión fluvial relacionada con el río Cuevas.

Acumulación de nieve invernal.
Detrimento estructural.

Alta

Detrimento estructural

Alta

Detrimento estructural

Media

leve. Desvalorización paisajística alta.

Desvalorización

Baja

paisajística.

Detrimento estructural

Media

Detrimento estructural

Alta

Detrimento estructural

Alta

Detrimento estructural.

Alta

Flexión de la estructura.

Baja

Gelifracción.

Media 
continuación tabla 1.

\begin{tabular}{|c|c|c|c|}
\hline Evidencias de fallas & Causas & Consecuencia & Incidencia \\
\hline Impacto directo. & $\begin{array}{l}\text { Desplazamiento de rodados, animales y peatones } \\
\text { sobre la estructura. } \\
\text { Obras de mejoramiento caminero. } \\
\text { Obras de captación y conducción de aguas } \\
\text { termales. Construcción de baños. }\end{array}$ & $\begin{array}{l}\text { Modificación del } \\
\text { entorno natural } \\
\text { y original del } \\
\text { monumento. }\end{array}$ & Alta \\
\hline $\begin{array}{l}\text { Inestabilidad de los } \\
\text { baños. }\end{array}$ & $\begin{array}{l}\text { Deterioro de la parte estructural de los baños. } \\
\text { Factores sísmicos. Falta de mantenimiento. Carga } \\
\text { de la estructura natural sobre los baños } \\
\text { (ver figura 10a). }\end{array}$ & Colapso de los baños. & Alta \\
\hline $\begin{array}{l}\text { Asentamiento } \\
\text { diferencial de los } \\
\text { baños. }\end{array}$ & $\begin{array}{l}\text { Erosión, desprendimientos y deterioro. Factores } \\
\text { sísmicos. Falta de mantenimiento. }\end{array}$ & Colapso de los baños. & Media \\
\hline $\begin{array}{l}\text { Derrumbe del baño } \\
\text { inferior. }\end{array}$ & $\begin{array}{l}\text { Erosión y deterioro. Factores sísmicos. Falta de } \\
\text { mantenimiento. }\end{array}$ & Colapso del baño. & Alta \\
\hline $\begin{array}{l}\text { Elevación del nivel del } \\
\text { suelo en la bóveda. }\end{array}$ & $\begin{array}{l}\text { Circulación constante y caudalosa del agua termal } \\
\text { que proviene de los baños. }\end{array}$ & $\begin{array}{l}\text { Reducción de la altura } \\
\text { del techo de la bóveda. } \\
\text { Inaccesibilidad a la } \\
\text { bóveda. }\end{array}$ & Baja \\
\hline $\begin{array}{l}\text { Aumento de los } \\
\text { depósitos del desagüe } \\
\text { de los baños. }\end{array}$ & $\begin{array}{l}\text { Desagüe constante y caudaloso del agua termal } \\
\text { que proviene de los baños. }\end{array}$ & $\begin{array}{l}\text { Acreción en la parte } \\
\text { baja de los baños. }\end{array}$ & Muy baja \\
\hline $\begin{array}{l}\text { Elevación del nivel del } \\
\text { suelo en los baños. }\end{array}$ & $\begin{array}{l}\text { Circulación constante y caudalosa del agua termal } \\
\text { que proviene de las vertientes de los baños. }\end{array}$ & $\begin{array}{l}\text { Detrimento general de } \\
\text { la estructura edilicia. } \\
\text { Baños inoperables. }\end{array}$ & Media \\
\hline
\end{tabular}

a los grandes flujos de materiales clásticos que se depositaron en el valle del río Cuevas, proveniente de los megadeslizamientos originados en la pared sur del monte Aconcagua, los cuales provocaron represamientos que favorecieron localmente la cementación de dichos flujos a partir de las aguas termales. El proceso de formación habría comenzado hace aproximadamente 14.798-13.886 años AP, con el inicio de la cementación de los depósitos y la apertura del arco que conforma al puente hace aproximadamente 8.620-8.254 años AP, por la acción de la onda erosiva retrocedente del río Cuevas (Fauqué et al., 2009).

\section{Materiales y métodos}

\subsection{Análisis de la integridad de Puente del Inca}

Para el análisis de la estabilidad estructural del puente se estudiaron los procesos que lo llevan a su deterioro, como así también aquellos que coadyuvan a restablecerlo. En primera instancia, se recopilaron trabajos y estudios previos con el objeto de obtener información acerca de la evolución del estado de la estructura desde principios del siglo XX hasta la actualidad. Entre estos trabajos se encuentran los de Kittl (1941), Monteverde (1947, 1967), Ramos (1993), Rimoldi (1993), Rubio et al. (1993), Aguirre Urreta y Ramos (1996), Ferrari et al. (2002), Ramos et al. (2008), Ramos (2009) y Fauqué et al. (2009).

En el marco de las tareas de campo, se efectuó la inspección visual de aquellos sectores relevantes de la estructura (dovelas, estribos e intradós) en búsqueda de la presencia o evidencias de fallas o comportamiento irregular de la estructura y deterioros condicionantes de su estabilidad (Tabla 1). Posteriormente se ponderó la incidencia de cada una de ellas sobre la integridad del puente. 
A su vez, se procedió a la caracterización de los manantiales termales a fin de clasificar y estudiar los depósitos de travertinos y su relación con los procesos geobiológicos que intervienen en la restitución/ formación del puente. Para ello, se dividió el ambiente geotermal del Puente del Inca en 4 sectores termales denominados: Fuente Copa de Champagne (FCC), Baño Desagüe Este (BDE), Baño Desagüe Sur (BDS) y Túnel Hotel-Baño (THB) (Fig. 2). Cada uno de estos sectores, fueron divididos en tramos determinados a partir de las distintas características que adquieren los manantiales conforme a cómo el agua termal fluye desde el punto surgente hasta su desagüe al río Cuevas. La diferenciación de algunas de estas características se basó en el trabajo realizado por Fouke (2011), el cual estudió la depositación de travertino de acuerdo con diferentes morfologías, texturas y mineralogía. Estas tareas fueron realizadas en octubre 2014 y tuvieron en consideración la valoración paisajística, la incidencia sobre la estructura, la actividad termal, el caudal (cualitativo), la morfología, la densidad y el color de las comunidades microbianas y la relación cualitativa caudal/área, de cada manantial termal. La valoración paisajística se definió de acuerdo con la gradación de colores generada sobre la superficie del puente, que se traduce en un atractivo visual para los visitantes. En relación con la incidencia sobre la estructura, se consideró el derrame de los manantiales termales sobre aéreas relevantes que influyen en la estabilidad del puente, tales como dovelas, estribos e intradós.

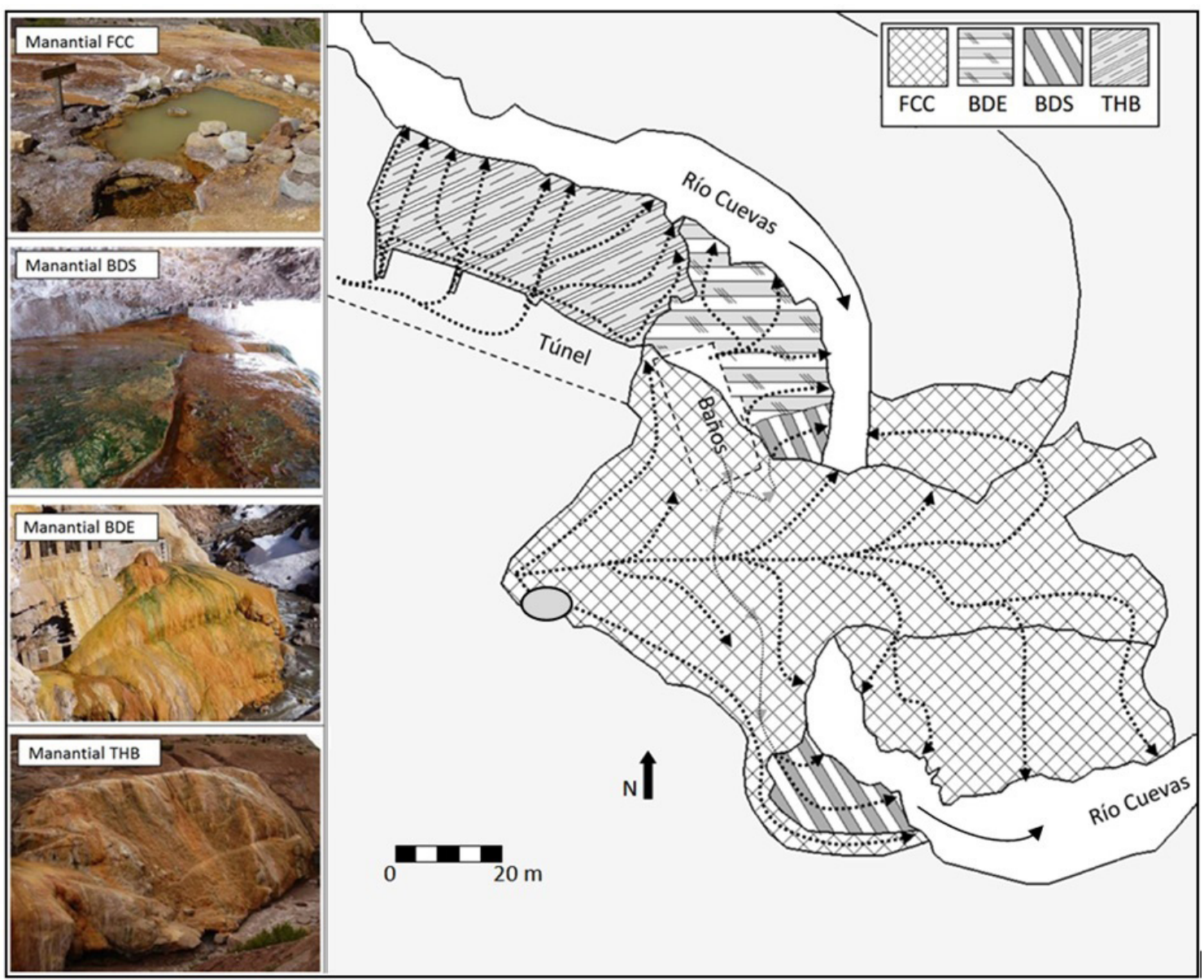

FIG. 2. Fotografías y esquema de ubicación de los sectores termales del Puente del Inca: Fuente Copa de Champagne (FCC), Baño Desagüe Este (BDE), Baño Desagüe Sur (BDS) y Túnel Hotel-Baño (THB). Las flechas y líneas segmentadas indican la dirección de flujo de las aguas termales. La elipse gris representa el punto de surgencia de la Fuente Copa de Champagne. 
Además, se midieron las tasas de acreción de los carbonatos con la finalidad de estudiar la regeneración del travertino. La formación de travertino es un proceso único, en el sentido que la depositación y erosión pueden estudiarse simultáneamente (Pentecost, 2005). Teniendo en cuenta esto, se diseñó un sistema formado por un conjunto de varillas cilíndricas de aluminio, graduadas milimétricamente, que permite estimar los cambios de nivel en la superficie a lo largo del tiempo (detalle de fotografía en figura 3A). En total se instalaron (22 octubre del 2014) 15 varillas distribuidas en la superficie del puente (P1-P15, ver figura $3 \mathrm{~A}$ ) y se efectuaron 4 sets de mediciones. La primera de ellas se realizó el 22/10/2014 y se repitió el procedimiento en las siguientes fechas: $30 / 09 / 2015,12 / 12 / 2015$ y 22/02/2016. A partir de estas mediciones, se calculó la tasa promedio de acreción para cada sector (FCC, BDE, BDS, THB) mediante la variación del nivel del depósito de travertino tomados en las varillas. Esta metodología para caracterizar los manantiales termales puede sentar las bases para construir un registro con los cambios y la evolución que experimenta en el tiempo el ambiente hidrotermal del Puente del Inca.

\subsection{Ensayo de los materiales que componen el puente}

No hay en la bibliografía antecedentes de trabajos que aborden el estudio de las propiedades mecánicas del material travertínico que compone el Puente del Inca. Si bien en la literatura pueden hallarse parámetros que caracterizan mecánicamente al travertino, no puede asegurarse que estos representen con exactitud los que componen al puente. En consecuencia, se procedió a la realización de ensayos geotécnicos de materiales sobre muestras consideradas como más representativas de la estructura. El criterio de elección de los sitios de muestreo apuntó a diferenciar heterogeneidades a partir de sus propiedades mecánicas.

En tal sentido, y considerando los antecedentes de estudios previos y procesos que intervienen en la formación de la geoforma natural, se propone la hipótesis de que el puente está compuesto en forma discreta por cuatro capas, a saber: superficial, media, base y estalactitas (Fig. 3B). La capa superficial (muestras M01, M04, M08 y M09) se asocia a un travertino externo, mientras la media (muestras M02, M03 y M07) está vinculada a sectores internos de la estructura. Teniendo en cuenta la depositación ascendente del travertino, la capa superficial corresponde a un material más reciente y la media a uno más antiguo. La capa denominada base (muestra M06) está formada por material detrítico cementado por la acción de las aguas termales. Finalmente, la capa estalactitas (muestra M05) se asocia con los precipitados minerales que penden del intradós del puente.

A partir de las 9 muestras mencionadas se obtuvieron 13 probetas de $54 \mathrm{~mm}$ de diámetro (indicadas como 1A, 2A, 3A, 3B, 4A, 5A, 6A, 6B, 7A, 7B, 8A, 8B, 9A, Fig. 3C) para el ensayo mecánico. El número de la probeta corresponde a la muestra, mientras que la letra indica las distintas probetas por muestra. Los ensayos fueron realizados en el Instituto Técnico de Investigaciones y Ensayo de Materiales (ITIEM), perteneciente a la Facultad de Ingeniería de la Universidad Nacional de Cuyo, Argentina. A partir de métodos por compresión simple (ECS) y ultrasónicos (EUS) se determinaron la densidad aparente $(\rho)$, el módulo de elasticidad (E), el coeficiente de Poisson (v) y la resistencia a la compresión $(\sigma c)$ y a la tracción $(\sigma \mathrm{t})$ del material.

Dado que existen períodos donde el agua termal deja de surgir -sobre todo en la Fuente Copa de Champagne (Figs. 2 y 3 )- el material que compone el puente puede presentarse seco o saturado. Por tal motivo, teniendo en cuenta estas condiciones, se realizaron los ensayos tanto sobre probetas secas como saturadas.

\subsection{Modelado numérico}

El modelado numérico estructural del Puente del Inca se basó en el desarrollado por Lannutti (2017) implementado a partir del Método de Elementos Finitos (MEF). En la actualidad, MEF es ampliamente utilizado en el ámbito científico e ingenieril para resolver numéricamente problemas estructurales (Bathe, 2008). El modelo numérico planteado para el presente estudio requiere como datos de entrada los parámetros mecánicos del material que constituye la estructura, la geometría 3D del puente y la designación de restricciones. Para definir estas últimas, se asumió que los estribos del puente están fijos (ver figura de la tabla 1).

\subsubsection{Datos de entrada}

La caracterización mecánica del material se obtuvo a partir de los ensayos de laboratorio (ver sección 3.2). La geometría 3D del puente se determinó con la 


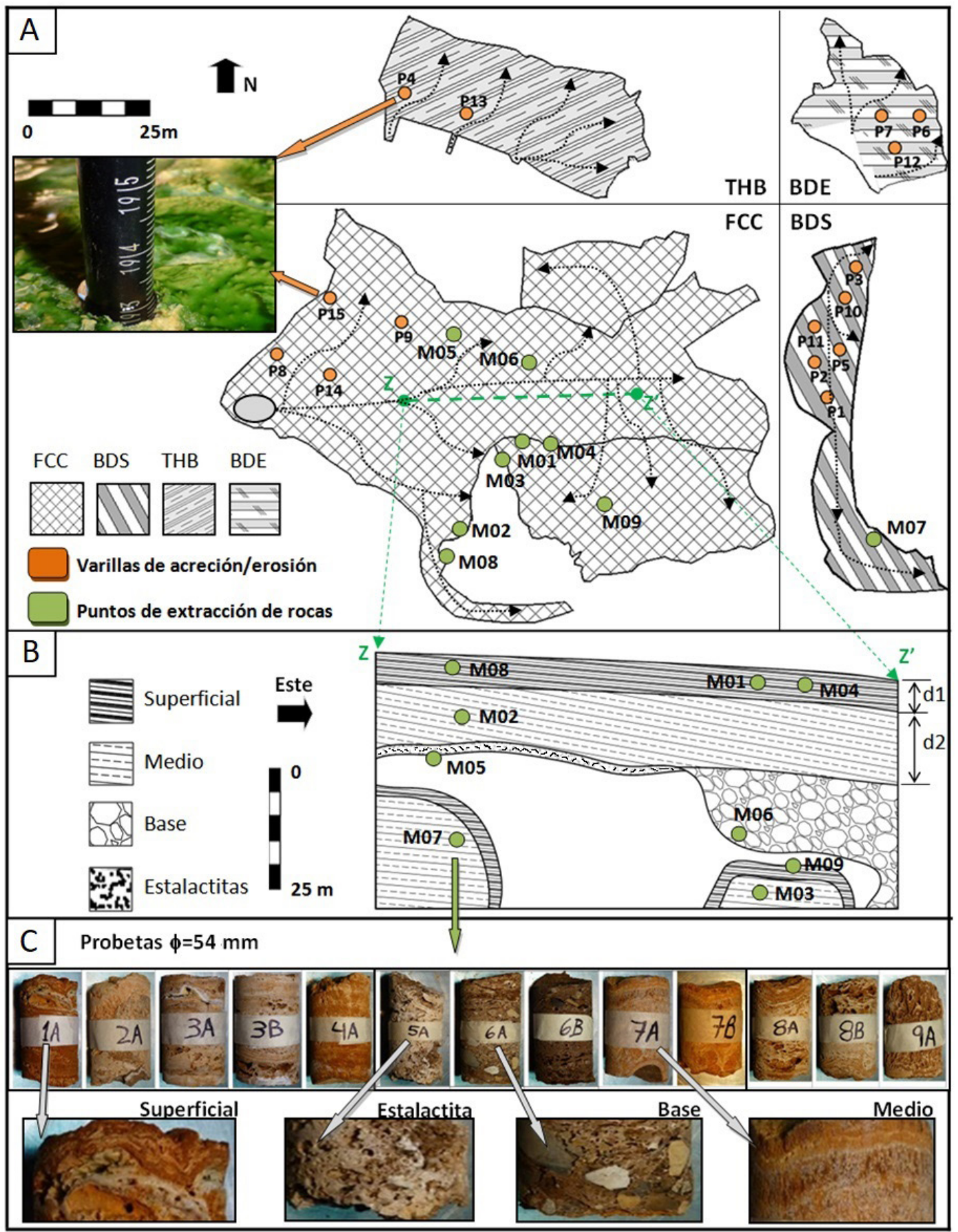

FIG. 3. A. Esquema con los 4 sectores termales: Fuente Copa de Champagne (FCC), Baño Desagüe Este (BDE), Baño Desagüe Sur (BDS) y Túnel Hotel-Baño (THB)) divididos para su mejor visualización. Fotografía de varillas de medición de acreción/erosión y sus puntos de localización sobre el puente (círculos color naranja). Lugar de extracción de las muestras de rocas (círculos color verdes) para ensayo de materiales. B. Corte longitudinal Z-Z' (línea segmentada verde en 3A), en el que se indican los puntos de muestreo de rocas referidas a las capas superficial-media-base-estalactitas; d1 y d2 son los espesores de la capa superficial y media, respectivamente, propuestas en el modelo numérico estructural (ver sección 3.3). C. Fotografías de las 13 probetas obtenidas a partir de las muestras de rocas y cuatro imágenes con ejemplos en detalle de las muestras, una para cada capa. 
técnica SFM (Structure From Motion), que emplea sistemas de visión computacional y algoritmos fotogramétricos (Smith et al., 2015) para obtener representaciones 3D (nubes de puntos densos) a partir de secuencias temporales y espaciales de imágenes $2 \mathrm{D}$. La fotogrametría estereoscópica convencional y la SFM operan bajo los mismos principios, la principal diferencia es que para construir la geometría de la escena, las posiciones de la cámara y la orientación se resuelven de manera automática (Westoby et al., 2012). Para generar la secuencia de imágenes se tomaron 372 fotografías a lo largo del puente mediante una cámara digital réflex NIKON D5300 (sensor CMOS DX de 24,2 megapíxeles, distancia focal fija de $35 \mathrm{~mm}$ ). El procesamiento y georreferenciación se llevó a cabo con el software de código abierto VisualSFM (Wu et al., 2011; Wu, 2013). El escalado y la georreferenciación de la nube de puntos se realizó mediante la implementación de 15 Puntos de Control Fotogramétricos en el Terreno (PCFT), logrados mediante mediciones GPS.

\subsubsection{Diseño del modelo y simulación}

A partir de las variables de entrada señaladas en los párrafos precedentes, se diseñó el modelo estructural computacional del Puente del Inca mediante el software de simulación ANSYS Student. De las modelaciones numéricas llevadas a cabo por Lannutti (2017), surgieron distintos modelos teóricos que representan el comportamiento estructural del puente. Finalmente se optó por aquel representado por una estructura formada por tres capas (superficial, media y base) debido a que en el proceso de optimización este obtuvo el menor error $(2,6 \%)$. La cuarta capa, relacionada con las estalactitas que penden del intradós del puente, no fue incorporada en el modelo por cuestiones de simplificación y escasa incidencia desde el punto de vista estructural.

En la figura 4 se entregan los valores de los parámetros mecánicos $(\rho=$ densidad aparente, $\mathrm{Ed}=$ módulo de elasticidad dinámico, $v=$ coeficiente de Poisson, $\sigma_{c}=$ resistencia a la compresión, $\sigma_{t}=$ resistencia a la tracción, $\mathrm{d} 1=$ espesor de la capa superficial

\begin{tabular}{|c|c|c|}
\hline \multicolumn{2}{|c|}{ Parámetros mecánicos } & \multirow[t]{8}{*}{ Geometría (SFM) } \\
\hline \multicolumn{2}{|c|}{ Superficial } & \\
\hline$\rho\left[\mathrm{kg} / \mathrm{m}^{3}\right]$ & 549 & \\
\hline $\mathrm{Ed}[\mathrm{GPa}]$ & 10,03 & \\
\hline$\sigma_{c}[\mathrm{Mpa}]$ & 2,24 & \\
\hline$\sigma_{\mathrm{t}}[\mathrm{Mpa}]$ & 0,66 & \\
\hline $\mathrm{d} 1$ [m] & 0,45 & \\
\hline$v$ & 0,32 & \\
\hline \multicolumn{2}{|c|}{ Media } & \\
\hline$\rho\left[\mathrm{kg} / \mathrm{m}^{3}\right]$ & 1.915 & \\
\hline $\mathrm{Ed}[\mathrm{GPa}]$ & 31,74 & \\
\hline$\sigma_{c}[\mathrm{Mpa}]$ & 8,06 & \\
\hline$\sigma_{\mathrm{t}}[\mathrm{Mpa}]$ & 1,42 & \\
\hline $\mathrm{d} 2[\mathrm{~m}]$ & 9,7 & \\
\hline$v$ & 0,32 & \\
\hline \multicolumn{2}{|c|}{ Base } & \\
\hline$\rho\left[\mathrm{kg} / \mathrm{m}^{3}\right]$ & 1.410 & \\
\hline Ed [GPa] & 13,04 & \\
\hline$\sigma_{c}[\mathrm{Mpa}]$ & 4,53 & \\
\hline$\sigma_{\mathrm{t}}[\mathrm{Mpa}]$ & 1,02 & \\
\hline$v$ & 0,32 & \\
\hline
\end{tabular}

FIG. 4. Parámetros geomecánicos de los materiales que componen el puente y la geometría utilizados para el modelo numérico estructural del Puente del Inca: $\boldsymbol{\rho}=$ densidad aparente, $\mathbf{E d}=$ módulo de elasticidad dinámico, $\mathbf{v}=$ coeficiente de Poisson, $\boldsymbol{\sigma}_{\mathrm{c}}=$ resistencia a la compresión, $\boldsymbol{\sigma}_{\mathbf{t}}=$ resistencia a la tracción, $\mathbf{d} \mathbf{1}=$ espesor de la capa superficial y $\mathbf{d} \mathbf{2}=$ espesor de la capa media. 
y d2=espesor de la capa media) que describen el modelo. A partir de este, se realizaron simulaciones de comportamiento estructural con el objetivo de reconocer los sectores más vulnerables y evaluar la estabilidad de la estructura natural. Las simulaciones consistieron en un análisis estático para determinar los desplazamientos y tensiones experimentados por el puente bajo la carga ejercida por el propio peso de la estructura. La estabilidad fue establecida mediante la estimación del Factor de Seguridad (FS) basado en el criterio de rotura Mohr-Coulomb (Lawrence, 2012). El FS es una magnitud que establece qué tan apartadas están las relaciones de las tensiones del valor unitario. Valores menores a la unidad representan puntos que son propensos a la ruptura o falla y valores mayores o iguales a la unidad establecen que el material ha superado el criterio de falla, por lo tanto, no está en situación de ruptura.

\section{Resultados}

\subsection{Deterioro del puente natural}

La tabla 1 muestra un resumen integral con las evidencias de fallas o comportamiento irregular de la estructura, relacionadas con el deterioro del puente, así como las causas, consecuencias e incidencia de cada una de ellas en dicho proceso.

\subsection{Restitución del puente natural y descripción de los manantiales.}

La estabilidad estructural del puente está relacionada con los procesos geobiológicos actuales de depositación de travertino a partir de las fuentes termales, por lo que el análisis de estos manantiales resulta necesario para el estudio de la restitución del monumento, entendiendo por tal la mejora de la estabilidad a partir del engrosamiento y la consolidación de la estructura del puente.

Las figuras 5, 6, 7 y 8 resumen la caracterización de los manantiales termales para los sectores Fuente Copa de Champagne (FCC), Baño Desagüe Este (BDE), Baño Desagüe Sur (BDS) y Túnel Hotel Baño (THB), respectivamente. En ellas se señalan tanto los tramos que corresponden a las distintas etapas de tránsito del agua termal, desde el punto de surgencia hasta su desagüe o volcado al río Cuevas, como las características de cada manantial y las tasas de acreción promedio.

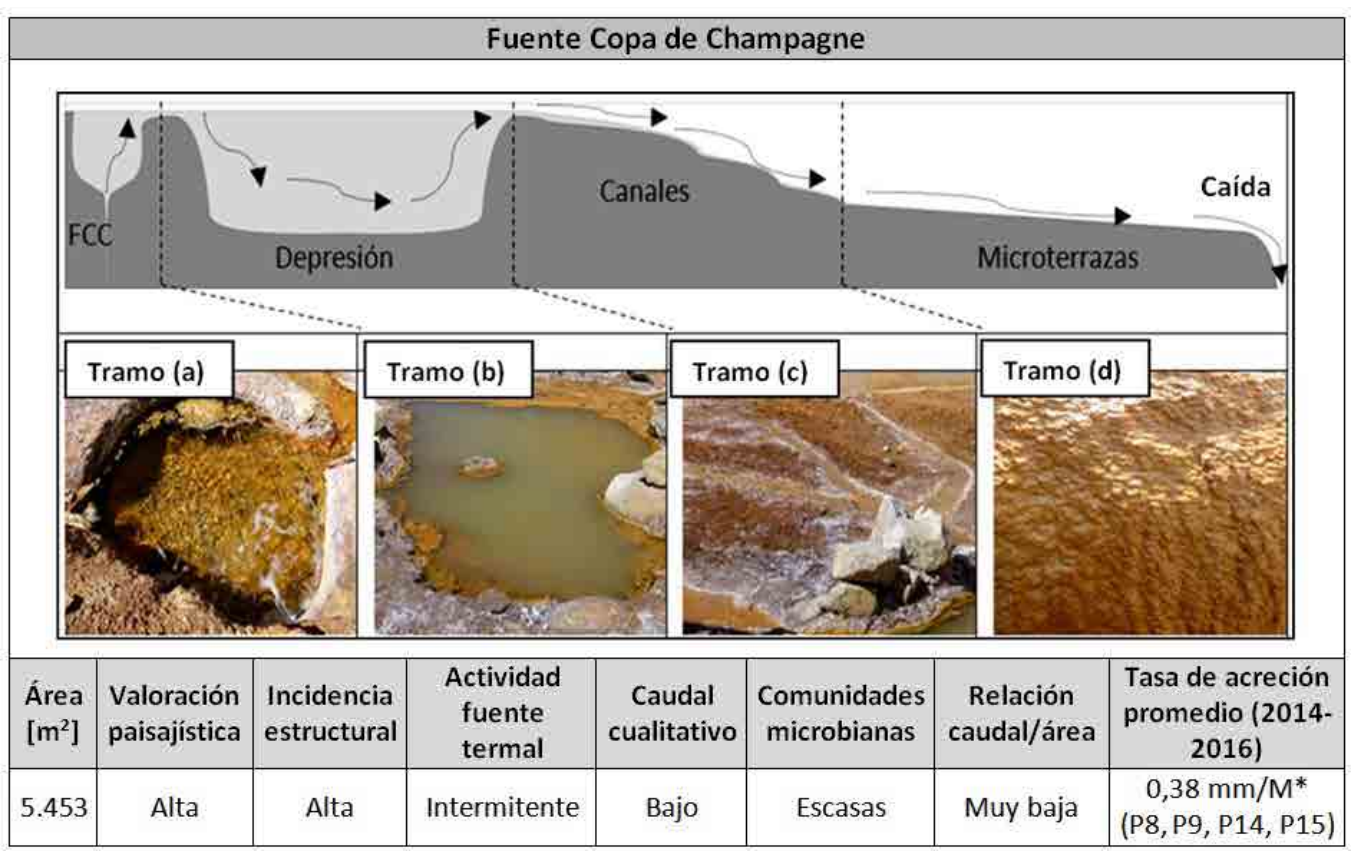

FIG. 5. Caracterización del sector termal Fuente Copa de Champagne (FCC), con identificación de los diferentes tramos reconocidos a lo largo del flujo de agua termal, desde la surgencia hasta su caída al río. $\mathrm{M}^{*}$ corresponde a mes. 


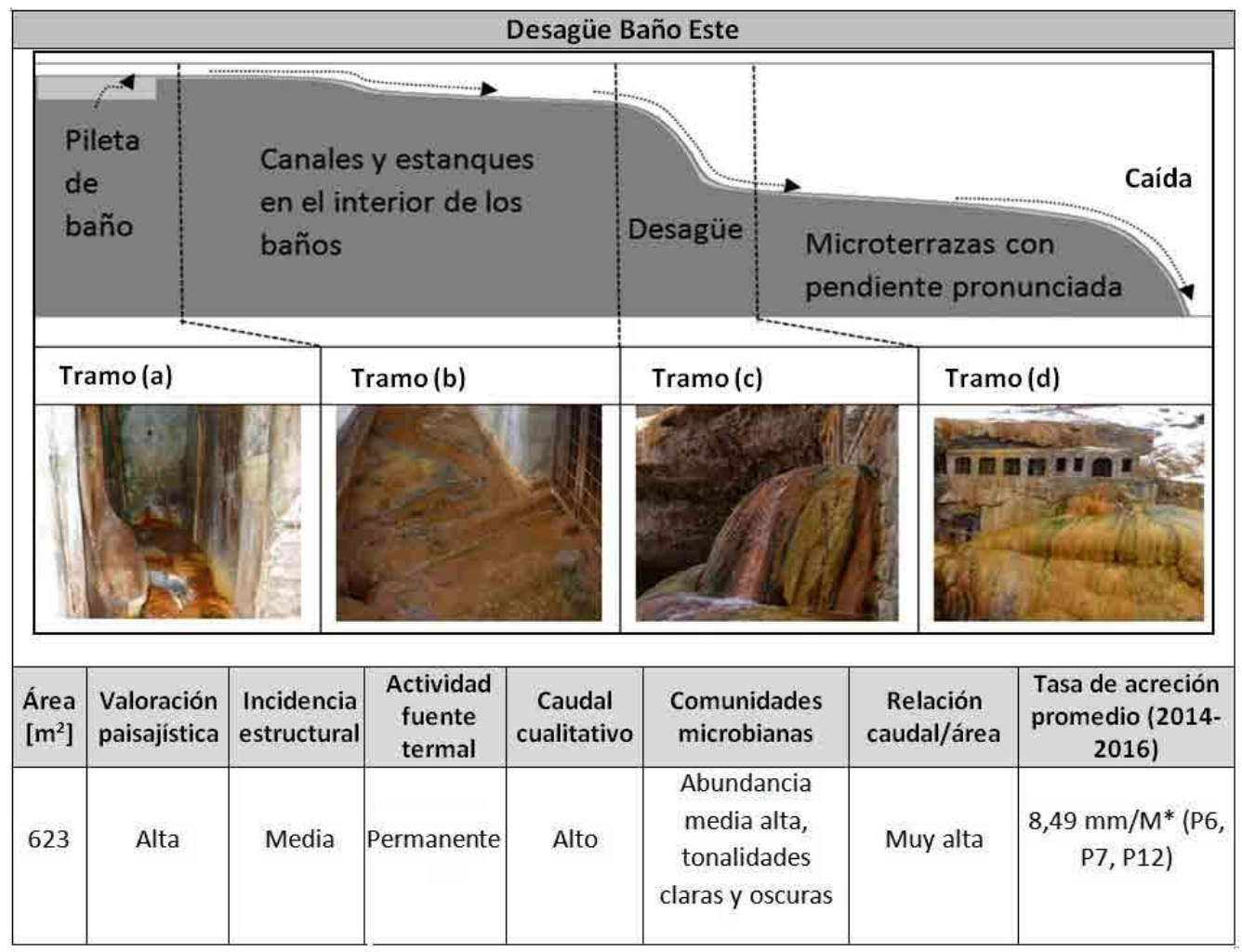

FIG. 6. Caracterización del sector termal Baño Desagüe Este (BDE), con identificación de los diferentes tramos reconocidos a lo largo del flujo de agua termal, desde la surgencia hasta su caída al río. M* corresponde a mes.

El manantial termal de FCC tiene modificaciones recurrentes relacionadas con la variación natural de su caudal. El tramo (a), una depresión con forma de olla o cuenco, comienza con el surgimiento del agua termal en la superficie (Fig. 5). En este punto el flujo es turbulento y transparente, con burbujas que ascienden hasta la superficie y no se aprecia gran concentración de comunidades microbianas. Luego, el agua se encauza por un canal estrecho hasta alcanzar una segunda depresión más extensa. En este tramo, (b), el flujo es lento y presenta mayor turbidez. Se distingue la presencia de microorganismos de colores beige, naranjas, marrón y, en menor cantidad, verdes. La depresión presenta cuatro aberturas por donde el agua fluye y desciende hacia los sectores más bajos de la superficie del puente. Al salir del tramo (b), el flujo se concentra por canales de origen antrópico, tramo (c). En estos la velocidad del flujo es alta debido a la canalización y la fuerte pendiente y no se evidencian poblaciones microbianas. En las inmediaciones de este tramo se observan terrazas formadas por flujos antiguos y algas ya extintas. El tramo (d) se origina a partir de las ramificaciones de los canales artificiales. Allí, el agua se distribuye en forma homogénea sobre la superficie del terreno. Aquí se pueden apreciar microterrazas actuales y antiguas, sobre las que existen pequeñas y dispersas comunidades microbianas de color verde claro. El recorrido del manantial termal concluye con su caída desde la superficie del puente al río Cuevas. Antes de su caída, FCC genera tres depósitos de travertino en forma de cascada en los vértices sureste, suroeste y noroeste del puente.

El manantial termal de BDE está compuesto por varias fuentes que surgen desde las piletas del pabellón de baños. Todas ellas presentan las mismas características y muestran cuatro tramos (Fig. 6). El tramo (a) corresponde al punto surgente del agua termal. Si bien no todas las fuentes brotan con el mismo caudal y turbulencia, todas fluyen del mismo modo a partir del desborde de las piletas. Desde allí, el agua fluye por el interior del edificio a través de 


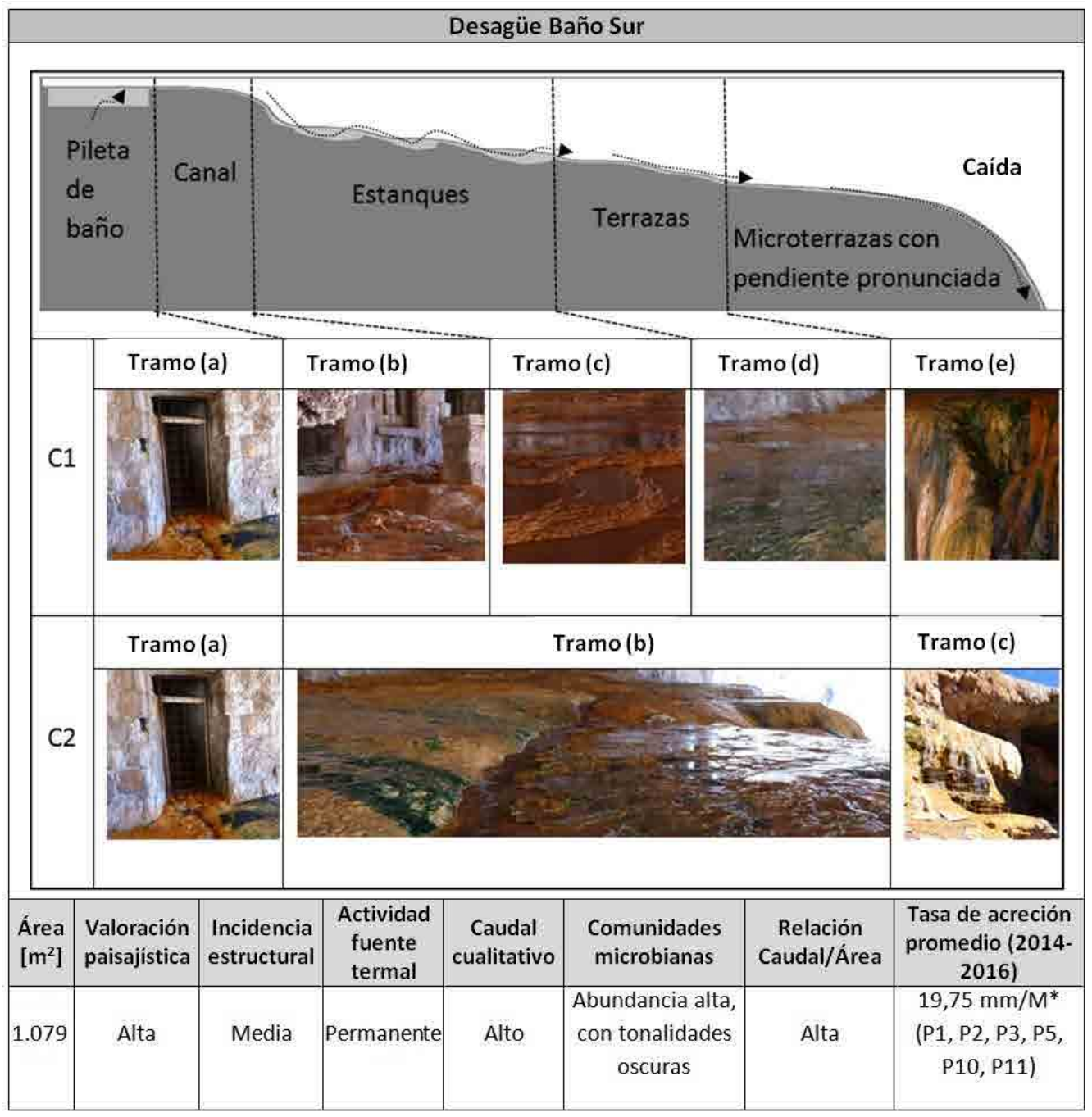

FIG. 7. Caracterización del sector termal Baño Desagüe Sur (BDS), con identificación de los diferentes tramos reconocidos a lo largo del flujo de agua termal, desde la surgencia hasta su caída al río para dos cursos de agua distintos: C1 y C2. En el curso C2 se reconocen solo tres tramos. $\mathrm{M}^{*}$ corresponde a mes.

canales y estanques con baja pendiente. En estos planos, que constituyen el tramo (b) se reconocen comunidades microbianas de color oscuro, que se tornan claras a medida que quedan expuestas a la luz solar fuera del edificio. En lugares con mayor incidencia de luz solar, las algas son más claras y crecen en menor cantidad (Ferrari et al., 2002). En la recova del baño sur y en la galería abierta del baño norte, el flujo se concentra y cae a través del desagüe en forma de cascada al exterior. Esta caída corresponde al tramo (c) y da origen a un relieve globular de gran colorido. Aquí el flujo es caudaloso y turbulento y se identifica presencia de microorganismos. En el tramo final, (d), el flujo se desacelera y distribuye homogéneamente sobre la superficie, hasta que cae en forma de cascada al río y se acelera nuevamente. En toda la superficie se aprecian terrazas y microterrazas en pendiente, con presencia de diversas comunidades microbianas de varias tonalidades de colores.

En el caso del manantial BDS, las aguas nacen también desde las piletas de los baños, y el tramo (a) de estas fuentes presenta las mismas características que las del Desagüe Este (BFE) (Fig. 7-C1). El tramo (b) 


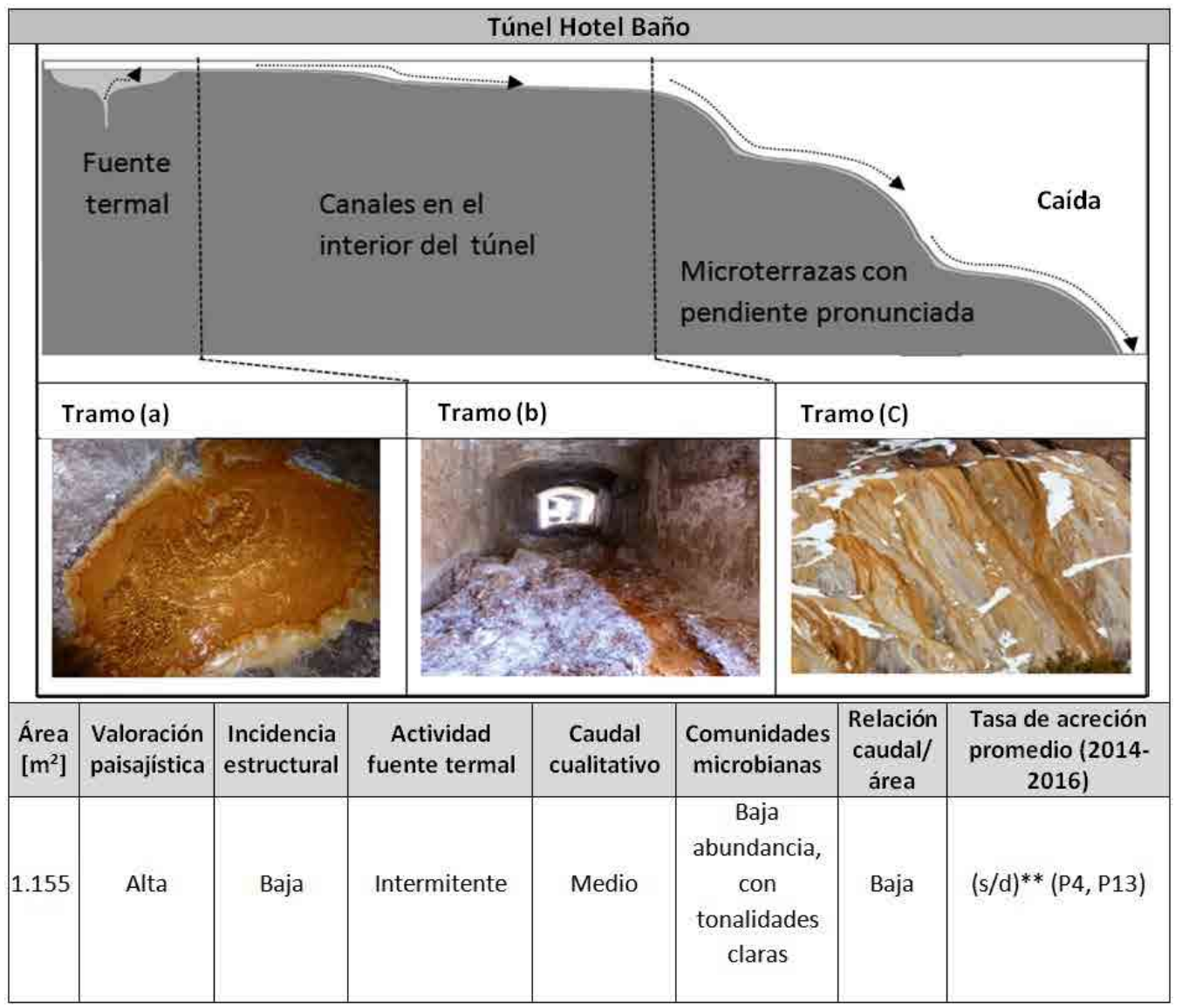

FIG. 8. Caracterización del sector termal Túnel Hotel Baño (THB), con identificación de los diferentes tramos reconocidos a lo largo del flujo de agua termal, desde la surgencia hasta su caída al río. (s/d)**sin datos.

corresponde a un canal por donde el agua corre de manera caudalosa y con alta velocidad. Se identifican algas verdes solo en los bordes paralelos al cauce. Por medio de ese canal, el agua se distribuye en un relieve plano por debajo de la bóveda del puente natural. A partir de allí se distingue el tramo (c), con formaciones de estanques con tonalidades naranjas y sin presencia de microorganismos. A medida que el agua fluye, se distribuye sobre un relieve compuesto por terrazas, área que corresponde al tramo (d) y es el sector actual con la mayor densidad de comunidades microbianas en todo el ambiente geotermal del monumento natural. Esto está relacionado con la continuidad de la actividad termal, con la menor cantidad de luz solar incidente en forma directa y con el relieve extenso y plano que favorece un flujo laminar y uniforme. El tramo (e) presenta las mismas características que la cascada descrita en el tramo (d) del BDE, con la única diferencia que muestra algas de color más oscuro. Cabe señalar que BDS puede ser subdividido en dos flujos: el C1, descrito anteriormente, corresponde al que se extiende por debajo de la bóveda y el C2, a la parte del agua que se encauza más al sur a través de un extenso canal. La caracterización de este último es similar a C1, con la salvedad de que no posee tramos (c) y (d) y la longitud del tramo (b) es mayor (Fig. 7-C2).

THB es un manantial que nace en el interior del túnel que antiguamente conectaba el edificio del hotel con el pabellón de baños. Tiene 3 tramos, a decir: fuente, canal y caída. Si bien a lo largo del túnel existen fuentes termales de diverso caudal, todas presentan la misma caracterización (Fig. 8). En el tramo (a) el agua brota del suelo y en el (b) el agua circula por canales en el interior del túnel. En este tramo, a diferencia de los canales de los otros 
sectores considerados, no existen comunidades microbianas y el flujo sale al exterior por medio de aberturas laterales en el túnel. El último tramo, (c), es la típica caída del agua termal al río mediante microterrazas con pendiente pronunciada, pero menos marcada en relación con los otros manantiales termales. Como indica la figura 8 , no se obtuvieron medidas de tasas de acreción/erosión debido a que se perdieron las varillas instaladas.

\subsection{Modelo numérico Puente del Inca}

\subsubsection{Ensayo de materiales y capas constituyentes del puente natural}

La figura 9 muestra los resultados y la variación de resistencia a la compresión $(\sigma c)$, de la resistencia a la tracción $(\sigma \mathrm{t})$, del módulo de elasticidad $(\mathrm{Ed})$ y de la densidad aparente $(\rho)$ de las probetas secas y saturadas agrupadas por capas. En términos relativos, la capa superficial (muestras M01, M04, M08 y M09) presenta bajos valores de resistencia a la compresión y a la tracción $(\sigma c \mathrm{y} \sigma \mathrm{t})$, mientras que el módulo de elasticidad dinámico (Ed) y de la densidad aparente $(\rho)$, resulta entre bajo y medio. Por su parte, la capa media (muestras M02, M03 y M07) tiene valores altos para estos cuatro parámetros. Las probetas provenientes de las capas base y estalactita (muestra M06 y M05 respectivamente) exhiben, en general, valores medios de $\sigma c, \sigma t, \mathrm{Ed}$ y $\rho$, salvo estalactitas que poseen bajos $\sigma \mathrm{c}$. El gráfico muestra una clara tendencia en ascenso de los valores de resistencia, elasticidad y densidad si agrupamos los resultados

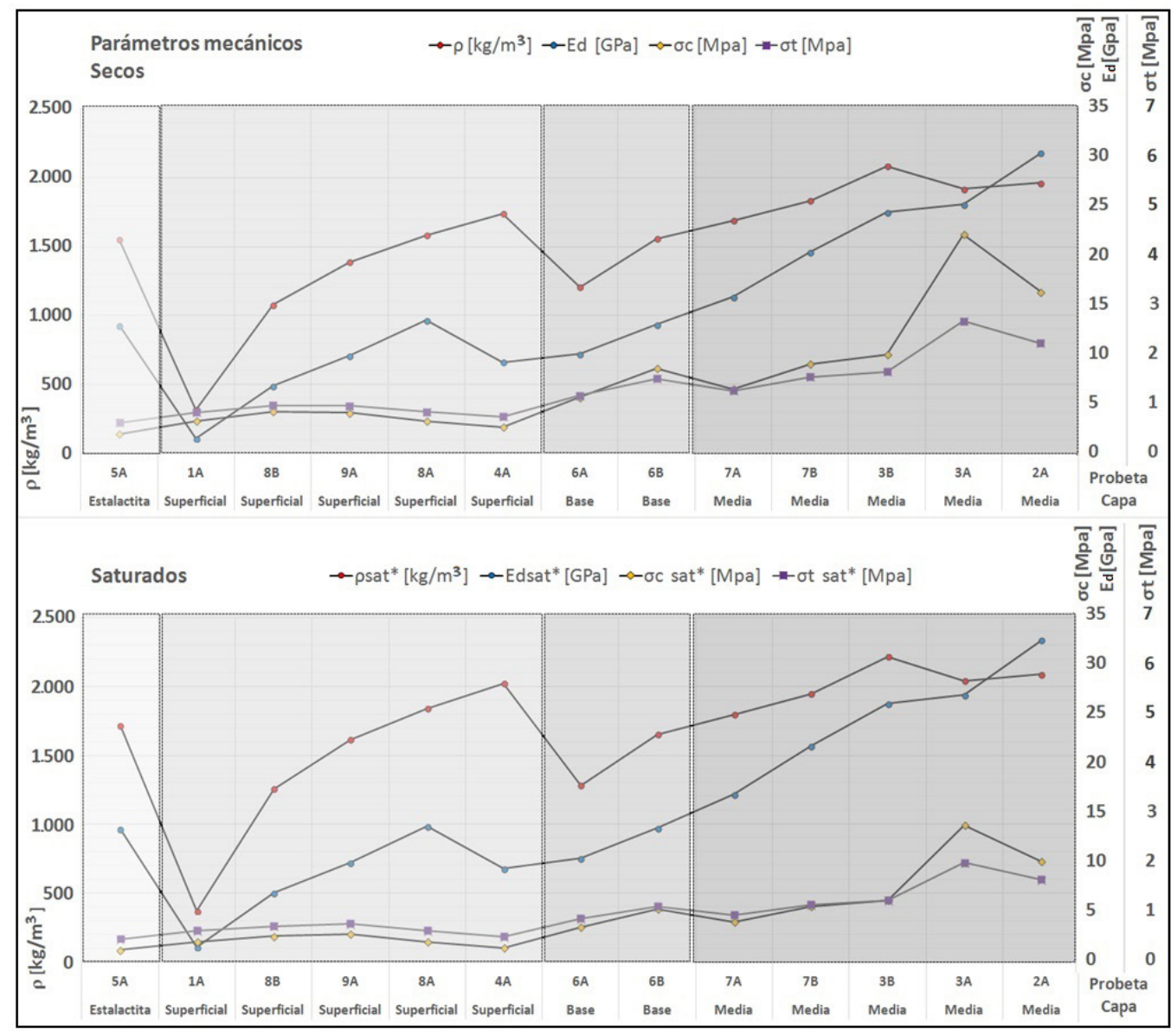

FIG. 9. Variación de resistencia a compresión $(\sigma c)$, resistencia a tracción $(\sigma t)$, módulo de elasticidad (Ed) y densidad aparente $(\rho)$ de las probetas secas y saturadas, agrupadas por capa estructural (estalactita-superficial-base-media) identificadas en el puente. sat* corresponde a saturación. 
en orden de capa superficial-base-media; estas tres capas son las más relevantes desde el punto de vista estructural. A su vez, puede observarse que, al comparar las condiciones secas frente a las saturadas, $\rho$ presentó un aumento promedio de $10,4 \%, \sigma c \mathrm{y}$ $\mathrm{t}$ disminuyeron un $37,2 \%$ y $24,8 \%$, respectivamente y Ed aumentó un 4,4\%. El coeficiente de Poisson ( $v$ ) es de 0,32 para todas las probetas ensayadas, tanto secas como saturadas.

También, de acuerdo con la pertenencia según cada capa, las muestras se diferencian desde el punto de vista macroscópico. Las probetas de la capa superficial presentan laminaciones con ondulaciones paralelas y gran porosidad (Fig. 3C, detalle fotografía probeta $1 \mathrm{~A}$ ), rasgos que pueden observarse en todas las probetas de la capa superficial (1A-4A-8A-8B9A, ver Fig. 3C). En cambio, en las que pertenecen a la capa media (sector más interno: 7A-7B-3B3A-2A) las laminaciones aparecen compactas y no hay espacio intersticial ni poros visibles (Fig. 3C, detalle fotografía probeta 7A). Las estalactitas (Fig. 3C, detalle fotografía probeta 5A) se muestran porosas y sin laminaciones, con espacios intersticiales redondeados con paredes tapizadas de minerales de color blanco, relacionados con los precipitados de sales que se forman en el intradós del puente. Por último, la capa base (probetas 6A-6B) está compuesta por material detrítico cementado por carbonato (Fig. 3C, detalle fotografía probeta $6 \mathrm{~A}$ ).

\subsubsection{Simulaciones estructurales}

A partir del modelo numérico propuesto en la sección 3.3.2, la figura 10A muestra la simulación de los desplazamientos totales y las tensiones a las que está sometida la estructura por la acción de su propio peso para materiales saturados de agua. En la parte central del tramo, sobre el borde norte, es donde se obtienen los mayores desplazamientos (1,2-1,5 mm). Esto se debe a la asimetría que presenta la geoforma en dirección norte-sur, y en cuyo borde septentrional se registra la mayor flecha y luz del puente. También, se destacan los desplazamientos y las tensiones sobre el pabellón de baños, lo que sugiere la interacción de estas estructuras con el puente.

Las tensiones se encuentran bien sectorizadas. Abarcan el sector de la dovela-estribo este, tanto lateral norte como sur-centro (0,5-2 MPa); el intradós medio (0,5-2,5 $\mathrm{MPa})$; el contacto puente-baño (1-4 MPa); el quiebre generado entre el intradós y el estribo oeste, que recorre el lateral de la bóveda, y las partes superiores de ambos estribos (1-2 MPa).

La figura 10B señala los resultados del cálculo del Factor de Seguridad (FS) de la estructura sometida a la acción de su propio peso, bajo condiciones de material saturado y seco. Ningún punto presenta valores menores a la unidad, lo cual establece que la geoforma es estable bajo su propio peso. Como muestra la figura, la estructura es más estable cuando el material no está saturado con agua termal, situación en la que presenta mayores valores de FS (debido a una mayor resistencia del material y menores valores de densidad aparente). Los FS más bajos corresponden a los sectores con mayores tensiones (descritos anteriormente) y en condiciones de saturación de agua, cuyos valores están comprendidos entre 1,5 y 8 . El sector más comprometido, con un valor de 1,5, es el intradós en la parte media del tramo, debido a que en este sector la estructura se flexiona y la parte superior se comprime, mientras que la parte inferior trabaja bajo tracción.

Otro sector que acusa bajos FS es el apoyo de la estructura natural sobre el baño principal sur, donde los FS alcanzan valores de 2,3 en el punto de contacto puente-baño. También se identifican bajos valores de FS, en los sectores que corresponden a los apoyos del tramo del puente con los estribos, cuyas fuerzas resultan significativas al distribuirse el peso total de la estructura en estos apoyos.

En la parte baja del puente, sobre todo en el área de intradós-dovela-estribo este (elipse punteada en Fig. 10B), es donde el trabajo de Monteverde (1967) y las observaciones realizadas en este estudio (ver Tabla 1) registran los mayores desprendimientos de material y adelgazamiento de la geoforma.

\section{Discusión}

Como demuestran los análisis cualitativos y cuantitativos de las probetas ensayadas (sección 4.3), la estructura natural del Puente del Inca no está compuesta por material travertínico homogéneo, sino por una capa de travertino superficial -formada por procesos geobiológicos-; una capa media, también de travertino, pero más densa y homogénea por la acción de procesos físicos y químicos; una base, conformada por material detrítico cementado por los carbonatos provenientes de las aguas termales, y por último, por un precipitado de minerales que forman estalactitas que penden del intradós del puente. 


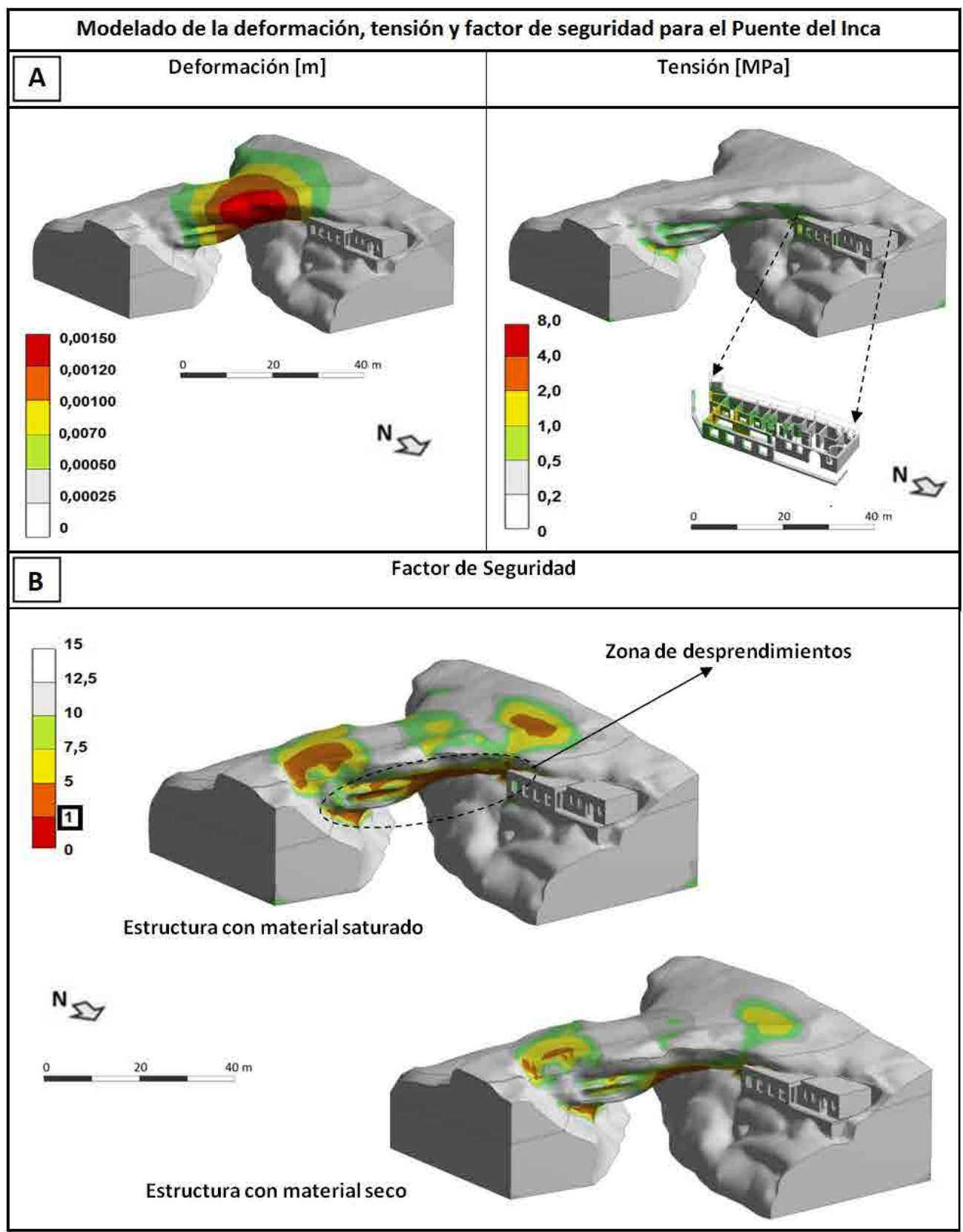

FIG. 10. A. Desplazamientos y tensiones estimadas a partir de la carga debida al peso propio de la estructura del puente, de acuerdo con los parámetros mecánicos ensayados para sus materiales en condiciones de saturación de agua. B. Factor de Seguridad para la estructura del puente sometida a su propio peso, sobre la base de los parámetros mecánicos del material en condiciones de saturación de agua y seco. La elipse punteada indica la zona donde se registran los mayores desprendimientos de material.

Esta diferenciación en capas pudo originarse a causa de un proceso ascendente de cementación y depositación del travertino. En este sentido, a partir del material base formado por sedimento detrítico cementado, empezó a acumularse material travertínico. A medida que este depósito incrementó su espesor, el material superficial comenzó a formar parte de la capa interna de la estructura, hasta alcanzar el espesor 
del puente actual. La estructura de la capa superficial está relacionada con la depositación de carbonato de calcio inducido por la actividad de las comunidades microbianas que crecen en la superficie, las cuales, en su proceso fotosintético, generan los rasgos característicos de laminaciones con ondulaciones paralelas y alta porosidad en el material. Dado que por debajo de esta capa la actividad fotosintética no puede desarrollarse, la depositación está principalmente dominada por procesos químicos y físicos vinculados a la pérdida de dióxido de carbono. El espacio entre las laminaciones antiguas es rellenado por la precipitación de carbonato de calcio intersticial a medida que el agua termal se infiltra hacia los sectores internos del puente. Por este motivo, en la capa media, las laminaciones resultan más homogéneas y compactas, lo que explicaría la mayor resistencia y densidad del material de esta capa. La figura 11 resume las características encontradas para cada una de las capas y una comparación relativa entre su resistencia $(\sigma)$, módulo de elasticidad (Ed) y densidad aparente $(\rho)$.

Lannutti (2017) establece que el modelo numérico que determina el comportamiento estructural más preciso, es uno discreto formado por una capa base por encima de la cual yace una capa media y otra superficial de 9,7 y 0,45 $\mathrm{m}$ de espesor, respectivamente (ver distancias d1 y d2 en los esquemas de la Fig. 3B y Fig. 4). En la estructura del puente es posible distinguir el límite entre la capa media y la base, ya que el tramo del puente -parte que se apoya en los

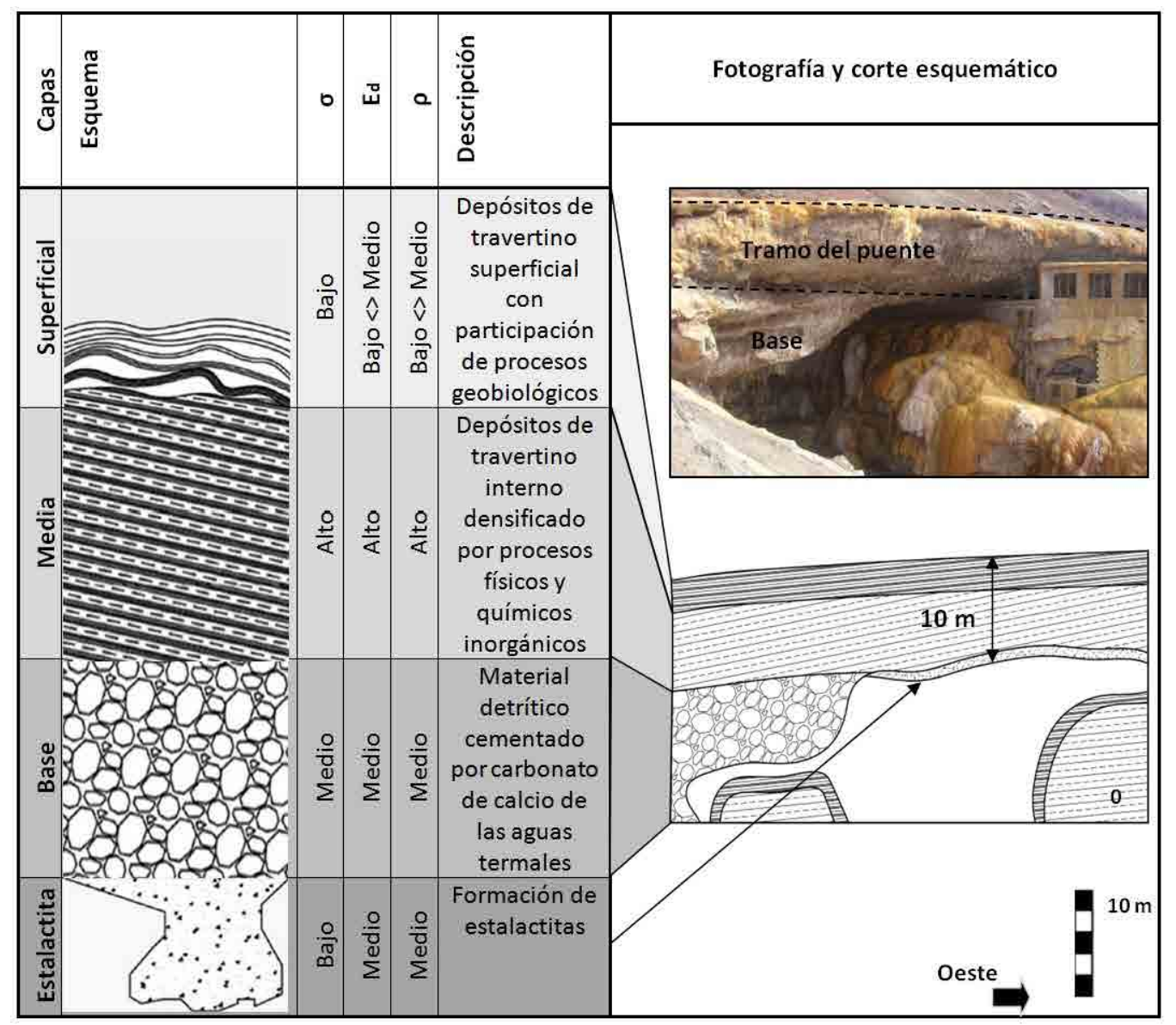

FIG. 11. Esquema con la descripción de las cuatro capas que conforman la estructura del puente natural. Análisis comparativo entre capas de acuerdo con la resistencia $(\sigma)$, del módulo de elasticidad (E) y la densidad aparente $(\rho)$ obtenidos en el ensayo geotécnico de materiales. A la derecha, fotografía y corte esquemático del Puente del Inca donde se destaca el tramo de $10 \mathrm{~m}$ de espesor que coincide con el del travertino determinado en el modelo numérico estructural. 
estribos y cruza por encima del río Cuevas- tiene un espesor de $10 \mathrm{~m}$, coincidente con el espesor determinado por el modelo numérico (fotografía y esquema en Fig. 11). El bajo error obtenido para el modelo numérico estructural $(2,6 \%)$ y la evidencia del límite de la capa media, indicarían que la estructura propuesta resulta una aproximación válida para el puente.

La morfología actual del Puente del Inca corresponde, desde el punto de vista ingenieril, a un puente en viga con tramo apoyado en estribos, característica que condiciona significativamente su estabilidad. El trabajo de flexión en el sector medio del tramo del puente hace que el límite de estabilidad esté determinado por la resistencia a la tracción del intradós. Las simulaciones estructurales de la figura 10A y B muestran este comportamiento. Los desplazamientos sufridos por la estructura frente a su propio peso flexionan el tramo del puente, trabajando el sector medio del intradós a esfuerzos de tracción, en donde se acusan los menores factores de seguridad.

Diversos autores, como Kittl (1941), Monteverde (1967), Ramos (1993), Rimoldi (1993), Rubio et al. (1993) e incluso el presente trabajo, señalan la importancia y el papel preponderante de las aguas termales en la preservación de la integridad de la geoforma. Como muestran los resultados de la sección 4.2, si los caudales de las fuentes termales surgen de manera abundante y continua, por ejemplo en los sectores Baño Desagüe Este y Baño Desagüe Sur, las tasas de acreción de travertino alcanzadas $(\mathrm{BDE}=19,75 \mathrm{~mm} / \mathrm{mes}$, $\mathrm{BDS}=8,49 \mathrm{~mm} / \mathrm{mes}$ ) producen significativos aumentos de espesor, lo que favorecería el engrosamiento y la cohesión del material, y le imprimiría una mayor estabilidad a la estructura. Por otro lado, la temperatura del agua termal también ayuda a la disminución de la meteorización física de gelifracción de la roca. No obstante, como indica el ensayo de materiales y la simulación del modelo numérico estructural, la pérdida de resistencia a compresión y tracción del material y el aumento de la densidad aparente en condiciones de saturación, producen una disminución del Factor de Seguridad (ver Fig. 10B), en definitiva de su estabilidad. Esta contraposición, abre una nueva discusión acerca de si es conveniente mantener irrigada la superficie del puente desde el punto de vista estructural. Para obtener más información resulta relevante efectuar un estudio específico del resultado del balance de la depositación de travertino y su cohesión, frente a la pérdida de la resistencia y la ganancia del peso del material en condiciones de saturación.
Por otro lado, debido al cambio súbito de dirección de este a sur del río Cuevas (ver esquema Fig. 2), la erosión fluvial tiene mayor incidencia en el estribo este que en el oeste. Al mismo tiempo, las aguas termales brotan en la margen oeste del río, esto genera que la tasa de depositación de travertino sea más alta en el sector oeste del puente. Estos dos procesos provocan que la estructura presente una mayor tasa de pérdida de volumen de material en el sector este en relación con el oeste, y provoque un desplazamiento de la exposición del Puente hacia el este.

\section{Conclusiones}

La integridad estructural de Puente del Inca está íntimamente relacionada con el equilibrio dinámico entre erosión y depositación de travertino. Desde sus orígenes, los procesos erosivos le han dado la forma característica de puente a partir de los desprendimientos de material de la parte baja de la estructura. El detrimento general de la estructura natural está relacionado principalmente con el deterioro de los estribos, dovelas y con la parte media del tramo del puente causado tanto por la erosión (hídrica y eólica) como por la meteorización y sismicidad, y la socavación de los estribos producida por la erosión fluvial del río.

Cuando las aguas termales, especialmente la Fuente Copa de Champagne, merman su caudal, la tasa de depositación de travertino se ve afectada. En principio, este aspecto condiciona la estabilidad del puente, al disminuir el engrosamiento y la cohesión del material de la estructura. Al mismo tiempo, las simulaciones realizadas en el modelo numérico indican que la irrigación termal afecta la estabilidad del puente, debido a la disminución del Factor de Seguridad de la estructura. Ambos criterios contrapuestos redefinen un mejor modo de restituir al monumento. Por lo tanto, la eficiencia en la distribución del agua termal, debe considerar en forma simultánea tanto el engrosamiento de la estructura como también la pérdida de resistencia y el aumento de la densidad aparente del material en condiciones de saturación.

Por otro lado, los resultados del modelo numérico indican que el puente es estable frente a su propio peso, con Factores de Seguridad (FS) estimados mayores a la unidad en todos los sectores de la estructura. No obstante, existen sectores con FS comprendidos entre 1,5 y 3 entre los que se destaca como valor más bajo 
el intradós en la parte media del tramo del puente. Comparado con criterios de diseño de obras civiles -en los que se utilizan FS por encima de 2 cuando no puede asegurarse la confiabilidad de los materiales y las condiciones de los factores externos que inciden sobre la carga y las tensiones a la cual es sometida la estructura- este valor es bajo. Entonces, si bien el puente resulta estable frente a su propio peso, los valores de FS bajos -sobre todo en condiciones de saturación de agua- alertan acerca de una estabilidad condicionada que invita a un monitoreo continuo, a fin de planificar medidas de preservación que mantengan las condiciones actuales y, en definitiva, aseguren la integridad estructural del puente.

\section{Agradecimientos}

Este trabajo fue subvencionado por la Agencia Nacional de Promoción Científica y Tecnológica, Argentina PICT SISMICO No $07 / 00264$. Los autores quieren agradecer a la Dirección de Recursos Naturales Renovables de la provincia de Mendoza y a los guardaparques Seccional Puente del Inca. Y, además, agradecer al Departamento de Geomática IANIGLA-CONICET y a A. Rubio, D. Trombotto, D. Gómez, E. Bottegal, M. González, M. Rosas, R. Zaradnik, R. Branham, R. Smalley, R. Bruce y S. Crespo.

\section{Referencias}

Aguirre Urreta, M.B.; Ramos, V.A. 1996. Áreas de Interés. In Geología de la Región del Aconcagua (Ramos, V.A.; editor). Anales de la Dirección Nacional del Servicio Geológico, Subsecretaría de Minería 24 (15): 471-480. Buenos Aires.

Bathe, K.J. 2008. Finite Element Method. Wiley Encyclopedia of Computer Science and Engineering. doi: 10.1002/9780470050118.ecse159.

Darwin, C. 1838. Journal of Researches into the Natural History and Geology of the countries visited during the voyage of the H.M.S. Beagle around the world. John Murray: 512 p. Londres.

Fauqué, L.; Hermanns, R.; Hewitt, K.; Rosas, M.; Wilson, C.; Baumann, V.; Di Tommaso, I. 2009. Megadeslizamientos de la pared sur del Cerro Aconcagua y su relación con depósitos asignados a la glaciación Pleistocena. Revista de la Asociación Geológica Argentina 65 (4): 691-712.

Ferrari, S.G.; Italiano, M.C.; Silva, H J. 2002. Effect of a cyanobacterial community on calcium carbonate precipitation in Puente del Inca (Mendoza, Argentina). Acta Botanica Croatica 61 (1): 1-9.
Fouke, B.W. 2011. Hot-Spring Systems Geobiology: abiotic and biotic influences on travertine formation at Mammoth Hot Springs, Yellowstone National Park, USA. Sedimentology 58 (1): 170-219.

Fouke, B.W.; Farmer, J.D.; Des Marais, D.J.; Pratt, L.; Sturchio, N.C.; Burns, P.C.; Discipulo, M.K. 2000. Depositional facies and aqueous-solid geochemistry of travertine-depositing hot springs (Angel Terrace, Mammoth Hot Springs, Yellowstone National Park, USA). Journal of Sedimentary Research 70 (3): 565-585.

Kittl, E. 1941. El Puente del Inca, su formación y conservación. Revista Minera 12 (3-4): 110-122. Buenos Aires.

Lannutti, E. 2017. Modelado numérico mediante la técnica de SHM (Structure Health Monitoring) aplicado a una estructura natural. Caso de estudio: Monumento Natural Puente del Inca. Tesis de Doctorado (Inédito), Universidad Nacional de Cuyo, Facultad de Ingeniería: $231 \mathrm{p}$.

Lannutti, E.; Lenzano, M.G.; Barón, J.; Lenzano, L.E. 2017. Using ground-penetrating radar to investigate the internal structure of Puente del Inca, Mendoza, Argentina. Near Surface Geophysics 15 (2): 175-186. doi: 10.3997/1873-0604.2017004.

Lawrence, K.L. 2012. ANSYS Workbench Tutorial Release 14, Structural \& Thermal Analysis Using the ANSYS Workbench Release 14 Environment. Sharof Development Corporation (SDC) Publication, Mission.

Monteverde, A. 1947. Origen del Puente del Inca. Revista La Ingeniería 866: 775-791. Buenos Aires.

Monteverde, A. 1967. Preservación del Puente del Inca. Revista Caminos 34 (295): 28-36. Buenos Aires.

Pentecost, A. 2005. Travertine. Springer Science and Business Media: 445 p. Berlin.

Ramos, V.A. 1993. Geología y estructura de Puente del Inca y el control tectónico de sus aguas termales. Simposio sobre puente del Inca. In Congreso Geológico Argentino No. 12 y Congreso de Exploración de Hidrocarburos, No. 2, Actas 5: 8-19. Buenos Aires.

Ramos, V.A. 2009. Darwin at Puente del Inca: observations on the formation of the Inca's bridge and mountain building. Revista de la Asociación Geológica Argentina 64 (1): 170-179.

Ramos, V.A.; Cegarra, M.; Pérez, D.J.; Miranda, F. 2008. Puente del Inca: ingeniería natural. In Sitios de Interés Geológico de la República Argentina, Servicio Geológico Minero Argentino (SEGEMAR), Anales 46: 203-214. Buenos Aires.

Rimoldi, H. 1993. Puente del Inca un monumento natural comprometido. In Congreso Geológico Argentino 
No. 12 y Congreso de Exploración de Hidrocarburos, No. 2, Actas TV: 20-23.

Rubio, H.A.; Santilli, C.A.; Salomón, M.A. 1993. Puente del Inca: Restauración y preservación. In Congreso Geológico Argentino, No. 12 y Congreso de Exploración de Hidrocarburos, No. 2, Actas 5: 20-23. Mendoza.

Schiller, W.1907. Geologische Unterschungenbei Puente del Inca (Aconcagua). Vorläufige Mitteilung. Neues Jahrbuch für Mineralogie, Paläontologie und Geologie, Beilage Band 24: 716-736.

Smith, M.W.; Carrivick, J.L.; Quincey, D.J. 2015. Structure from motion photogrammetry in physical geography. Progress in Physical Geography 40 (2): 247-275. doi: 10.1177/0309133315615805.
Westoby, M.J.; Brasington, J.; Glasser, N.F.; Hambrey, M.J.; Reynolds, J.M. 2012. "Structure-from-Motion" photogrammetry: A low-cost, effective tool for geoscience applications. Geomorphology 179: 300-314.

$\mathrm{Wu}$, C. 2013. Towards linear-time incremental structure from motion. In International Conference on 3D Vision-3DV. Institute of Electrical and Electronics Engineers (IEEE): 127-134.

Wu, C.; Agarwal, S.; Curless, B.; Seitz, S.M. 2011. Multicore bundle adjustment. In Computer Vision and Pattern Recognition (CVPR), Institute of Electrical and Electronics Engineers Conference: $3057-$ 3064.

Manuscript received: December 12, 2017; revised/accepted: April 4, 2019; available online: January 31, 2020. 